\title{
Connectivity in Emerging Regions: The Need for Improved Technology and Business Models
}

Rahul Tongia, Carnegie Mellon University

\begin{abstract}
The digital divide is a pressing challenge for both technology and policy professionals. Connectivity is one aspect of the divide, albeit an important one. Availability and affordability remain important issues, but these depend on not only technology choices, but also business and regulatory models. While mobile phones have achieved spectacular growth in emerging regions, Internet access, especially broadband, lags far behind. A generalized model of costing broadband indicates that limited uplinking (interconnection) is a significant barrier to widespread and affordable connectivity, but last mile access also remains a challenge. In addition, policy distortions and regulations raise costs dramatically. Because of these, new technologies, business models, and regulations may be required to make connectivity available and affordable in emerging economies. These include advanced wireless technologies, greater fiber utilization, and open access networking.
\end{abstract}

\section{INTRODUCTION}

Infrastructure is expensive, and in emerging regions especially, many projects such as water systems or power plants barely break even or require ongoing subsidies. Telecommunications are unique - most projects are profitable, sometimes immensely so, and the sector continues to draw significant investment, both public and private. Part of this stems from continual improvement in technology, which surpasses even Moore's Law.

Two factors stand out for emerging regions. First, the deployment levels of telecommunications are markedly lower than in developed countries. Second, the growth rates are often enormously higher. What has led to such growth? The answer is a combination of technology as well as business/regulatory models.

We begin with a deeper look at the digital divide, and examine generalizations and specifics of technology solutions for connectivity. We show how new business models and new technologies can go hand in hand to allow leapfrogging.

\section{UNDERSTANDING THE DIGITAL DIVIDE}

\section{Connectivity AND the Digital Divide}

At the end of the 20th century, there were numerous pronouncements lamenting that Manhattan had more phones than Africa. Not only was this possibly not true then, it is certainly not true today given the surge in mobile phones, crossing well over 10 percent of the population. Officially, users crossed 100 million recently from only about 8 million about five years ago.

Mobiles offer connectivity, or access, which is the first step toward opportunity [1]:

Access $\rightarrow$ Information $\rightarrow$ Knowledge $\rightarrow$ Opportunity

Connectivity is only one component of information and communications technology (ICT), which is considered to span the four Cs: computers (rather, devices), connectivity, content, and (human) capacity [1].

The digital divide is more than exclusion, and is often marked by the differences spanning awareness, availability (nearness), accessibility (including language and literacy), and affordability. Instead of just measures of penetration of technology, composite measures of the digital divide are most helpful, factoring cost of ICT services as well as human factors such as literacy. For example, the International Telecommunication Union (ITU) publishes the Digital Access Indicators (DAI) [2], excerpted in Table 1. It has multiple components, one of which is the relative cost of 20 hours of dialup Internet access per month, including local telephone charges. Of course, the "average" person in many countries does not go online (they do not have a computer), so such statistics need deeper interpretation. In reality, the digital divide is an extension of underlying divides across geography, income, 
Digital access indicator (DAI)

\begin{tabular}{|c|c|c|c|c|c|}
\hline $\begin{array}{l}\text { Highest } \\
\text { rank }\end{array}$ & & $\begin{array}{l}\text { Internet tariff } \\
\text { as } \% \text { of average } \\
\text { income }\end{array}$ & $\begin{array}{l}\text { Lowest } \\
\text { rank }\end{array}$ & & $\begin{array}{l}\text { Internet tariff } \\
\text { as } \% \text { of average } \\
\text { income }\end{array}$ \\
\hline 1 & Sweden & 1.1 & 164 & Eritrea & 200.9 \\
\hline 2 & Denmark & 0.7 & 165 & D.R. Congo & 986.7 \\
\hline 3 & Iceland & 0.9 & 166 & Benin & 146.5 \\
\hline 4 & Korea (Rep.) & 1.2 & 167 & Mozambique & 233.1 \\
\hline 5 & Norway & 0.8 & 168 & Angola & 143.3 \\
\hline 6 & Netherlands & 1.2 & 169 & Burundi & 703.2 \\
\hline 7 & Hong Kong, China & 0.2 & 170 & Guinea & 185.2 \\
\hline 8 & Finland & 1.1 & 171 & Sierra Leone & 857.1 \\
\hline 9 & Taiwan, China & 0.7 & 172 & Central African Rep. & 807.9 \\
\hline 10 & Canada & 0.7 & 173 & Ethiopia & 329.0 \\
\hline 11 & United States & 0.5 & 174 & Guinea-Bissau & 840.0 \\
\hline 12 & United Kingdom & 1.1 & 175 & Chad & 375.7 \\
\hline 13 & Switzerland & 0.7 & 176 & Mali & 289.8 \\
\hline 14 & Singapore & 0.6 & 177 & Burkina Faso & 247.5 \\
\hline 15 & Japan & 0.8 & 178 & Niger & 683.6 \\
\hline
\end{tabular}

Source: World Telecom Development Report 2003, ITU

Table 1. Relative cost of basic Internet access. This is for 20 hours of dialup access per month, including incremental local telephony charges, if any. These are the 15 highest and lowest ranking countries in terms of ITU's Digital Access Indicators. While incomes may vary significantly, there are large differences in absolute costs as well.

gender, age, and so on, and treating it as a cause instead of a symptom is a recipe for failure.

ICT can enable human development through efficiency, empowerment, and opportunities. However, in a world where many people struggle for daily subsistence, is ICT an appropriate technology? "The debate in the 1990 s over choosing between ICT and other development imperatives has now shifted from one of trade-offs to one of complementarity" [3]. That bridging the digital divide and harnessing ICT for development are important global tasks was underscored by the United Nations conferences on this topic, the World Summits on the Information Society (WSIS).

\section{Connectivity AND Metrics}

Is the mobile phone, as indicated in the March 10, 2005 Economist cover story, the solution to the digital divide? Or do we want Internet access, and, if so, how fast? Even if there were a universal definition of broadband, measurement difficulties abound. Most statistics are based on national numbers reported by the government, which usually sidestep issues of granularity and geography.
Most mobile phone subscribers in emerging regions are in urban areas. Figure 1 shows how in India, which not only has the highest growth rate for mobiles (recently adding over 6 million net subscribers/month) but also some of the lowest tariffs in the world (with a monthly average revenue per user [ARPU] below \$8), rural teledensity shows very low growth.

Availability and affordability are the two most important factors determining the connectivity divide. Even though footprints of mobile phone service in developing countries often exceed 50 or 60 percent of the population, and carriers are expanding rural coverage, the actual uptake is much lower, largely because of affordability. At an extreme level, anyone, anywhere can access voice and data communications - they must simply afford satellite-based services.

\section{ExPLAining ReCENT GROWTH OF MOBILES}

Until the 1990s, telephone penetration and growth was low in most developing countries because few lines were available (with waiting lists of years, often), and the services were expensive. Most countries had a government monopoly carrier.
Availability and affordability are the two most important factors determining the connectivity divide. Even though footprints of mobile phone service in developing countries often exceed 50

percent or 60 percent of the population, the actual uptake is much lower, largely because of affordability. 


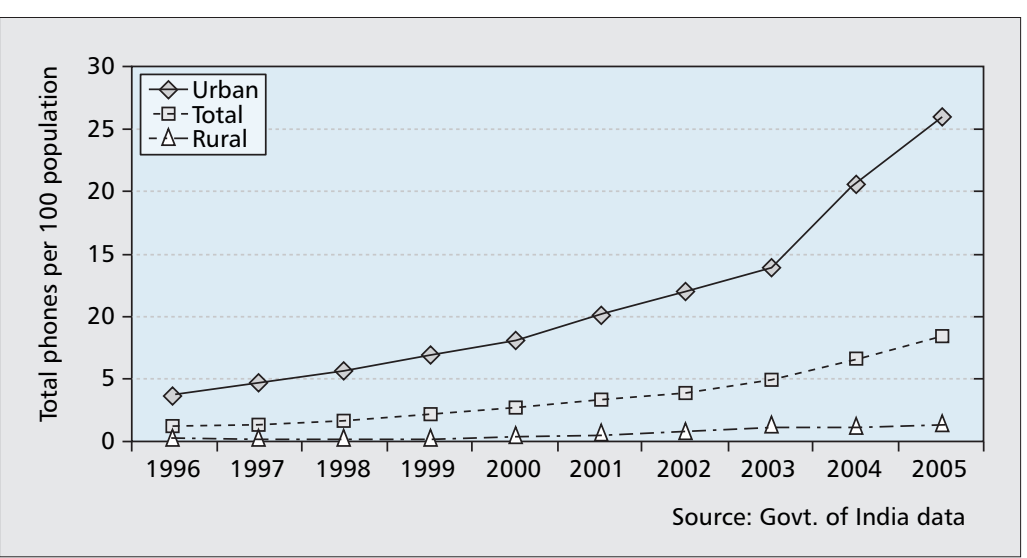

Figure 1. Teledensity in India.
Two changes occurred, hand in hand. First, mobile telephony emerged as a viable technology, for several times lower investment per subscriber than a landline. Second, governments allowed private entrants to provide mobile telephony, initially considering this a different service than landlines. Not only were there new entrants with money to invest, the market typically grew to more than one competing carrier.

Cell phones thrived across developing countries for various reasons including affordability, limited obstacles regarding literacy, low bandwidth requirements per call, and a competitive environment often pushed by private companies. While they also have become status symbols, they help meet a fundamental human need to communicate and share information.

\section{LIMITATIONS OF CURRENT SOLUTIONS AND DESIGNS}

While mobiles have addressed the voice market, data connectivity is a greater challenge. Current technologies, when considered for emerging regions, are often characterized as too expensive, but their capabilities may also be an issue. How much bandwidth is really required, and can mobiles deliver?

The rise of advanced consumer (edge-driven) applications, including blogs, torrents, wikis, podcasts, and shared video, part of what is termed Web 2.0 [4], indicates that traditional asymmetric pipes to consumers, as well as "broadband" that is charged per bit, may create further divides vis-à-vis consumers with flat tariff connections that allow unlimited megabit speed downloads and uploads. If the goal is the socalled triple play (voice, video, and broadband data), non-broadcast wireless may struggle to meet video requirements, especially high definition, which requires an estimated $10-20 \mathrm{Mb} / \mathrm{s}$.

Is video a driving force? In emerging economies entertainment (via cable TV or video CDs) is a much bigger industry than the Internet. The third largest movie industry in the world after Hollywood and Bollywood (India) is in Nigeria, despite having perhaps only a single movie theater. Over half of Indian homes (1.1 billion people) reportedly have a TV, and more than half of these pay for cable TV.
Many present cable TV buildouts are haphazard, by small franchisees, making the upgrade to broadband problematic. Converting even 10 percent of the population to broadband implies millions of connections per country, and this is a scalability challenge. Many broadband deployments today require provider installation, which works for niche deployments, but even inexpensive labor does not compensate for unavailable labor. Technology solutions need to be easier to install, require less highly specialized labor, and be robust in adverse environmental conditions (especially without air conditioning).

New definitions of robustness might be appropriate. 99.999 percent target reliability for telecommunications equipment is in stark contrast to the other challenges in terms of electricity, security, interconnection, and so on. Consumers and service providers should be able to utilize much cheaper solutions in exchange for slightly more unpredictability in terms of operations and performance. Skype, the software VoIP solution, displays varying levels of quality, but users, especially in emerging regions, happily accept this because they cannot complain about its price (free). Cutting edge solutions for quality of service (QoS) are also unlikely to gain market traction in emerging regions, which are very price-sensitive. Many networking professionals also believe the cheapest QoS solution is simply more bandwidth [5].

Even mobile phone standards may be overengineered for emerging regions, opening the way for newer solutions like voice over WLAN (WiFi phones). Discussions with technology providers indicate almost 30 percent of mobile phone system costs are for soft handoff between cells at vehicular speeds. Instead, portability may be a greater need, such that consumers can use the same instrument at different locations but not necessarily moving at $100+\mathrm{km} / \mathrm{h}$. WiFi phones might suffice, simultaneously enabling Internet access.

Power is an underappreciated challenge for emerging regions, and a number of countries have added population faster than electrification. With grid-based power unavailable (or intermittent), expensive standalone generation is required for cell towers and other telecommunications equipment. This calls for improved power management, especially for wireless (including mesh) networks.

Electricity is typically considered a utility with "must serve" obligations. Landlines might have such requirements upon the licensee, but mobile telephones? If one does not get a signal, there is little recourse. Regulators have rarely mandated universal service schemes to mobiles, and Internet access is even less "must serve," never mind broadband.

In developed countries, it took a combination of government intervention, preferential regulation, and universal service obligations to bring connectivity to rural areas. Privatization, the solution in vogue, is unlikely to be enough as for-profit companies naturally only seek the best markets for deployment. For starters, privatization is not the same as competition, and economists point out true competition needs at least three providers - how feasible are three different fibers to each home or even neighborhood, especially in rural Africa? 
Hardware

Equipment at central office, cable head-end, etc.; customer premises equipment - CPE (if provided)

Operating costs

Customer relations management; billing; maintenance

Regulatory fees (e.g., spectrum); marketing; promo-

One-time costs tional equipment (e.g., CPE); line conditioning/testing; installation

Uplinking or interconnection costs
Charges to connect to rest of global network (transit or backbone access charges)
Most providers leverage existing physical media, such as copper from phone lines or cable TV deployments; fiber is an exception and often greenfield

Synergies with other services can reduce these costs, e.g., landlines and DSL or cable TV and cable modem

Promotional or bundled plans often give away $\mathrm{CPE}$, or offer free installation with a contract

Depend heavily on rated speeds and level of oversubscription (statistical multiplexing)

Table 2. Components of broadband costs (techno-economic model). This is based on [6].

\begin{tabular}{|c|c|c|c|c|}
\hline & Hardware costs & Operating costs & One-time costs & Uplinking costs \\
\hline $\begin{array}{l}\text { Relative costs } \\
\text { in developing } \\
\text { countries }\end{array}$ & Higher (often) & Lower & Slightly lower & Much higher \\
\hline Select reasons & $\begin{array}{l}\text { 1. Import duties } \\
\text { 2. Low volumes } \\
\text { 3. High Interest rates } \\
\text { (cost of capital) } \\
\text { 4. Limited availability of } \\
\text { physical media (last- } \\
\text { mile copper) }\end{array}$ & $\begin{array}{l}\text { 1. Cheaper labor } \\
\text { 2. Lower customer } \\
\text { service burdens } \\
\text { (often) }\end{array}$ & $\begin{array}{l}\text { 1. Lower installation costs } \\
\text { (but skilled labor often } \\
\text { limited) } \\
\text { 2. Lower customer acquisition } \\
\text { costs (including marketing) } \\
\text { - possible artifact of less } \\
\text { competition }\end{array}$ & $\begin{array}{l}\text { 1. Dramatically higher backbone } \\
\text { interconnection (transit) costs } \\
\text { 2. Greater need to interconnect } \\
\text { - much less content is } \\
\text { "local," on the same service } \\
\text { provider network or even } \\
\text { within country }\end{array}$ \\
\hline Implications & $\begin{array}{l}\text { 1. Highest speed or } \\
\text { advanced solutions } \\
\text { often not chosen } \\
\text { 2. Greater reliance on } \\
\text { customer paying for } \\
\text { end-user device (less } \\
\text { free customer } \\
\text { modems or handsets) }\end{array}$ & $\begin{array}{l}\text { 1. Reliability of the } \\
\text { services may be } \\
\text { lower } \\
\text { 2. Fewer customer } \\
\text { remedies against } \\
\text { failure to meet } \\
\text { Service Level } \\
\text { Agreements }\end{array}$ & $\begin{array}{l}\text { 1. Limited marketing } \\
\text { impacts new subscriber } \\
\text { growth } \\
\text { 2. Adding a new customer } \\
\text { is more laborious (often, } \\
\text { not a customer self-install) }\end{array}$ & $\begin{array}{l}\text { 1. Much lower speed connections } \\
\text { are the norm } \\
\text { 2. Service is heavily oversubscribed } \\
\text { (statistically multiplexed) } \\
\text { 3. Flat rate pricing is rare or } \\
\text { expensive; usage-based is the } \\
\text { norm. This limits how } \\
\text { consumers use the service } \\
\text { (applications) }\end{array}$ \\
\hline
\end{tabular}

Table 3. Developing countries' broadband cost components relative to developed countries. In some cases a public provider may be willing to deploy services for low margins, something private companies may be unwilling to do.

\section{TECHNO-ECONOMIC MODELS OF CONNECTIVITY}

Before we can examine select technological and regulatory options for improved connectivity, we first consider a generalized model for connectivity, based on [6]. Other important issues such as devices, local content, literacy, and credit availability are acknowledged but not discussed further here.

This is a baseline model for a facilities-based Internet service provider (ISP) (they deploy their own equipment), who faces costs in four categories (Table 2). Naturally, comparing connectivity technologies is difficult because of the differences in features, capabilities, and backend requirements. Prices also differ from the costs, as the former depends on profit margins.

How do emerging economies fare in this framework (Table 3 )? With enough volume, hardware costs can be globally competitive, if not cheaper in developing countries - witness the very low cost seen for mobile telephony rollouts in India or low costs for DSL in China (from newspaper reports regarding bids).

If physical media is available on which to offer broadband access, an issue we revisit later, a major challenge is for uplinking, for either the ISP or the nation overall. Given mobile providers in Africa often have to build out their own backbones, with little or no fiber available to them, their wireless backhauls limit their ability to provide data services.

In much of the United States, although not necessarily in rural areas, an ISP can have backbone interconnection for roughly $\$ 100 / \mathrm{Mb} / \mathrm{s} / \mathrm{mo}$. In many parts of Africa, the cost can be over $\$ 5000 / \mathrm{Mb} / \mathrm{s} / \mathrm{mo}$ for satellite links, and the country may not even have an optical-fiber-based international gateway. Even when the country does have an international fiber gateway, such as 


Core backbone links
can be wireless,
especially microwave,
but wireless has
most potential as an
access technology.
However, the
dominant technology
was optimized for
voice, and even the
data-centric third
generation mobile
technology, 3G, is
limited in
deployment, and
expensive.

through SAT-3/WASC along West Africa, the prices are artificially high because the system endows monopoly rights to a particular provider, usually the incumbent. Unofficial estimates indicate that the loading (capacity in use compared to total possible bandwidth) on these links is only $\sim 10$ percent or lower, but the annual returns are on the order of 33 percent!

In India, connecting to the international gateway can cost more than the monthly charge of $\sim \$ 750 / \mathrm{Mb} / \mathrm{s}$ for an international leased circuit. This emphasizes the need for not only local and national links, but also greater local and domestic content. Regional peering can also help, such as through nascent Internet exchanges in subSaharan Africa, so traffic between neighboring countries does not have to peer in Europe. As a step toward better uplinking (replacing satellite), East Africa has proposed a consortium-based optical fiber system, Eastern Africa Submarine System (EASSy).

\section{TECHNOLOGY FOR IMPROVED CONNECTIVITY}

\section{THe NeEd fOR Fiber}

Most recent broadband $\mathrm{R} \& \mathrm{D}$ has been on access solutions, in part because this remains a challenge in developed regions as well and in part because viable solutions for the backbone exist, such as dense wavelength-division multiplexing (DWDM). However, most underserved regions, including much of the rural United States, do not have high-speed access links. Even if an intercity fiber passes nearby, without wavelength filters and add-drop multiplexers, this "express lane" does not make local stops. The "local loop" to an existing backbone point of presence can be enormously expensive given distancebased charges and limited competition.

As uplinking/backhaul options are crucial, simple capacity calculations show these should be fiber-based. The theoretical capacity is estimated at $\sim 100 \mathrm{~Tb} / \mathrm{s} /$ fiber strand, with commercial systems capable of multiple terabits per second today, and most deployments are bundles of dozens of strands; copper (like wireless) is not only capacity- but also distance-limited.

While fiber is considered expensive, manufacturing costs per kilometer bundle are now modest, especially using fiber manufactured in China or India. Reports indicate 48-strand bundles (standard single-mode fibers) are available for well under $\$ 1000 / \mathrm{km}$. Most telecom models indicate that laying fiber dominates the fiber costs. While somewhat true, emerging region costs can be an order of magnitude lower than in developed countries. Not only is labor cheaper, rights of way costs are also lower. Real-world numbers from India and China demonstrate this, with fiber bundles installed for $\sim \$ 2000 / \mathrm{km}$, including the fiber, trenching, ducting, splicing of fibers, and so on.

Fiber remains viable for large-capacity links, but for deeper links into a system (e.g., all the way to the home)? For a greenfield deployment the capital and digging costs may be similar to copper, making the solution "future-proof," but fiber is slightly harder to work with, and the ter- mination equipment costs more. However, fibers (like wireless) have one non-obvious advantage: virtually no theft, unlike copper, which can and has been dug out and resold.

\section{Wireless TeChNologies: Prime ACCESS SOlUtions}

Core backbone links can be wireless, especially microwave, but wireless has most potential as an access technology. Infrastructure costs scale nicely with deployment, and the shared nature of the medium matches the modest load levels of underserved regions. However, the dominant technology was optimized for voice, and even the data-centric third-generation ( $3 G)$ mobile technology is limited in deployment and expensive.

Many consider mobile phones a voice communications leapfrog ("bypassing an inferior or interim solution") over landlines, but the implications are not entirely positive. If the goal is data (broadband) connectivity, mobiles do not provide copper, which has been the primary mode for consumer broadband (DSL over twisted pair or cable modems over coaxial). Mobilephone-based broadband is nascent and faces challenges, discussed below. There are other leapfrogs available to emerging regions, such as deploying optical fiber instead of copper in local loops, or installing Cat5 cable in new buildings for Ethernet access.

There are two technical reasons $3 \mathrm{G}$ solutions might remain expensive or a niche solution for broadband, especially in developing countries. Spectrum is usually limited (under current regulations and deployments), and carriers earn more per bit carrying voice (or SMS/text messages) than data, which is often charged per byte. ITU specifications as deployed by many $3 \mathrm{G}$ solutions allocate only $5 \mathrm{MHz} / \mathrm{ch}$ annel. The spectral efficiency in practice is not much better than $1 \mathrm{Mb} / \mathrm{s} / \mathrm{MHz}$, increasing to only a few megabits per second per megahertz with enhancements such as High-Speed Downlink Packet Access (HSDPA), under ideal conditions. As this is shared per cell, a fundamental way to increase bandwidth to end users is to make the cell size smaller, which raises costs and is viable only in urban or niche areas.

Boosting emitted radiation levels is regulation limited, varying by country. The U.S. FCC limits are usually more generous than European or global European Telecommunications Standards Institute (ETSI) standards, especially when it comes to use of antennae for amplification. For example, FCC emission limits for WiFi (in 2.4 $\mathrm{GHz}$ ) allow a sliding scale of amplification for every $1 \mathrm{~dB}$ of reduction in active transmission, $3 \mathrm{~dB}$ of antenna gain is allowed (up to a ceiling); ETSI standards limit the total effective isentropic radiation to $20 \mathrm{dBm}$. If policies allow, advanced technologies such as multi-input multioutput (MIMO) technologies (also termed smart array antennae) should dramatically improve wireless communications.

While Shannon's Theorem would suggest greater bandwidth allocation for proportional capacity, simply changing the band could help as well. In addition to decreasing interference 
(especially in unlicensed bands, e.g. the industrial, scientific, and medical/universal national information infrastructure [ISM/UNII] 2.4 and $5.8 \mathrm{GHz}$ ), different frequencies have different propagation properties regarding distance and the ability to penetrate obstacles. One heuristic is that halving the frequency doubles the achievable range, which is now being exploited by code-division multiple access (CDMA) $450 \mathrm{MHz}$ systems.

Studies show that spectrum is poorly allocated and underutilized [7], epitomized by the ultra high frequency (UHF) TV band. Out of dozens of such over-the-air TV channels possible (each utilizing a bandwidth of 6 or $8 \mathrm{MHz}$, varying by country), very few places utilize even a dozen; we have not been able to identify a single African city that has allocated, let alone operationalized, more than eight channels. This excludes any shift to digital TV, which is more spectrally efficient.

Beyond policies allowing secondary markets and opening more bands, such as for unlicensed spectrum, advanced technologies such as underlay transmissions can help overcome interference issues and increase spectrum usage. Other innovations include the use of software defined radios (SDRs) and cognitive radios, which can be autonomously agile in terms of not only frequency but also modulation, power levels, and so on [8].

WiMax: An Emerging Technology - WiMax, the new standard for wireless wide area connectivity, has enormous potential for developing countries, and the new standard for mobile WiMax, 802.16e, competes with traditional cellular voice technologies. Technological advancements beyond $\mathrm{WiFi}$, itself a short-range option, include adaptive modulation so that the entire cell is not beholden to the worst link subscriber, and combining time- and frequency-division multiplexing in novel ways for the uplink and downlink. WiMax implements orthogonal frequency-division multiplexing (OFDM), which is expected to become the underlying technology for the fourth generation $(4 \mathrm{G})$ of wireless mobile communications, already being tested in Korea.

Wireless technologies such as WiMax are not without challenges. The upfront costs are relatively high; base stations today cost $\sim \$ 10-20,000$ and receivers $\sim \$ 250+$. In addition, the technology needs to be cautious about misleading claims - although they are by no means the only offenders. WiMax proponents indicate that the technology can go up to $70 \mathrm{Mb} / \mathrm{s}$, and up to 50 $\mathrm{km}$ (emphasis added). I can run 10 miles an hour, and carry $50 \mathrm{~kg}$. Not at the same time! The WiMax standard uses varying modulation quaternary phase shift keying (QPSK) to 64quadrature amplitude modulation (QAM) - to manage different users at different distances from the base station, so in a point-to-multipoint configuration it is not designed for $70 \mathrm{Mb} / \mathrm{s}$ across an entire large cell.

Initial WiMax certified devices will operate in the $2.5,3.5$, and $5.8 \mathrm{GHz}$ bands. Only the last one is unlicensed, and not in all countries. Could WiMax operate in the $700+\mathrm{MHz}$ (UHF) band if legal? Manufacturers could easily create chipsets to operate in this band since WiMax design separates the physical and medium access control (MAC) layers. One hopes that emerging regions open up this band before developed regions as such frequencies may be less encumbered there. How would manufacturers handle the varying global standards for frequency? It is possible that SDR or cognitive radio solutions could emerge, or manufacturers would simply bundle multiple chipsets together, as they do for $802.11 \mathrm{a} / \mathrm{b} / \mathrm{g}$.

Alternative Wireless Designs - Beyond access solutions, can commodity WiFi chipsets enable low-cost point-to-point links? There are many experiments ongoing to harness such WiFi chipsets (tens of dollars) for long-distance communications, and there are numerous successful rural WiFi backhauls. While such links may have much cheaper hardware than proprietary solutions (hundreds of dollars), for really long distances of many kilometers, the costs of installation (hundreds of dollars), a high antenna (thousands of dollars), reliable power (hundreds or thousands of dollars), physical security, and uplinking dominate the cost of the transceivers.

Blurring the line between last hop and metropolitan connectivity, wireless mesh networking technology is growing for city/regional wireless deployments, since this reduces the need for uplinking (vs. traditional cell-based designs). Reports indicate a total uplink of onesixth the cumulative user capacity is sufficient to make the mesh appear as if all users and nodes have full (direct) uplinking, although this depends on traffic patterns, especially video and peer-to-peer. The design also offers the possibility of greater robustness and load balancing, via ad hoc topologies. Most solutions today are proprietary, based on WiFi, but a standard is under development (IEEE 802.11s).

\section{Other TeChnology Trends}

Technology improvements may come through basic (or applied) R\&D, but major cost reductions necessitate widespread adoption (volume), which usually requires standards, ideally globally. Chipset costs depend primarily on the size of the chips (square millimeters of silicon) and the total volume of production. System-level costs, on the other hand, depend on design, architecture, and existing infrastructure, and here new technologies and protocols such as delay-tolerant and intermittent networking may have value. Other options where technology and policy intersect include standards combining telephony and IP (e.g., ENUM), spectrum allocations, and the rollout of IPv6.

\section{BUSINESS AND REGULATORY MODELS FOR IMPROVED CONNECTIVITY}

\section{IT'S MORE THAN THE TECHNOLOGY}

If viable technologies for networking exist, is the bottleneck just one of investment? Although marginal costs are very low, telecom networks face significant upfront costs.

One could theoretically drop in a solution
Beyond policies

allowing secondary

markets and opening

more bands, such as

for unlicensed

spectrum, advanced

technologies such

as underlay

transmissions can

help overcome

interference issues

and increase

spectrum usage.

Other innovations

include the use of

software defined

radios and

cognitive radios. 
The point is not

whether this is

affordable - only

the market will tell -

but whether these

higher costs make

the services

expensive for users.

One policy option is

regulatory surcharge

waivers in exchange

for open access and

rural deployment

requirements, or

perhaps for a core

public network. like a community access center in every village for $\sim \$ 1000-\$ 2000$, depending on the status of uplinking and electricity. This solution could be used for e-governance, distance learning, agricultural price discovery, and many other uses. It is unlikely that any one application alone could justify the investment, but the aggregated societal benefits could outweigh the costs. In the state of Andhra Pradesh in India, with a population over 75 million, a private entity is building out fiber to every village. The government is offering aggregated demand for megabit links, for providing or enabling the above public services, thus becoming an anchor tenant for expanded connectivity.

This underscores that access in poorer regions may be shared, instead of individual like in richer countries (mobiles exceed people in countries like Taiwan and Bahrain). Many people may not have a computer (or even a TV), but a neighborhood likely may. Shared access is cost effective, and it even allows entrepreneurship. Grameen Phone in Bangladesh is a highly successful program where women ("phone ladies") carry phones to clients around a village with a markup for their services. This concept of sharing access emerges even in European countries, with new entrants like FON and Free (a French ISP) offering shared access across their subscriber base. Such a business model offers hundreds of thousands of accessible hotspots, but it is disruptive to traditional telecom models (selling everyone a link) and violates many terms-of-use agreements as of today.

New business models were key to the success of mobiles in emerging regions. The technology itself was a trickle down from industrialized nations, with small innovations such as modified user interfaces and new methods for charging phones, including using car batteries. However, one under-heralded innovation was the advent of prepaid SIM cards, important to overcome issues of credit risk. This billing and accounting system has enabled mobile commerce and transferring money, ranging from transferring airtime to other users all the way to interfacing with banking establishments for cash transfers and withdrawals. This is an additional killer app for the technology, but it required the acquiescence of the mobile service provider.

\section{OPEN ACCESS NeTWORKING: Managing the Public-Private Debate}

While conventional wisdom states governments should not provide networking services themselves, what happens when companies find certain markets unattractive? The government may have to intervene for rural and underserved areas, through universal service norms or even direct provision of services. However, the Chilean experience shows that private enterprises can offer rural services through reverse subsidy auctions - asking how much subsidy they require. Through competition, the net subsidy became very low, and now most rural areas have service. The government should also be a strong independent regulator, setting the ground rules for companies, allocating spectrum, limiting monopoly actions, and so on.
As an answer to the digital divide, many communities are building out their own telecom networks, not only as municipal WiFi (e.g., Philadelphia, San Francisco) but even as fiber networks (Stockholm, Amsterdam, Utah, etc.). This need not be owned by the government, but can be established by private enterprises under regulatory guidelines such as unbundling - separating wholesale and retail services.

Such networks can apply open access models [9], which move away from service-based regulation (e.g., voice providers v.s data providers), instead treating connectivity as operating at different layers. Open access, linked to nondiscrimination and network neutrality, is especially important for fiber systems, as a single fiber pair can carry all of not only a person's but even a neighborhood's traffic. Facilities-based competition becomes expensive [10] (recall the need for three competitors), so open access (public utility) models of basic connectivity are gaining traction. The physical network (where fiber lasts decades) is built for open access (either publicly or privately), but retail competition (with electronics to be amortized in years) can occur at the edges.

The earlier section on techno-economics of connectivity indicated that competition, new technologies, and so on can all lower the costs of hardware, deployment, and uplinking. However, there are many regulatory and policy distortions that increase costs tremendously. These include import duties, spectrum charges, licensing fees, rights-of-way charges, monopoly interconnection and international gateway frameworks, restrictions on applications and services such as VoIP, and so on [6,9]; these can cost much more than the technology. Recently, Egypt's auction for the third provider license of GSM $(+3 \mathrm{G})$ fetched almost US\$3 billion, plus 6 percent revenue share. Making reasonable assumptions about penetration levels and costs of capital, this implies $\$ 6-8 /$ month is the licensing fee alone, which is many times higher than estimated technology costs.

The point is not whether this is affordable only the market will tell - but, too, whether these higher costs make the services expensive for select users. One policy option is regulatory surcharge waivers in exchange for open access and rural deployment requirements, or perhaps for a core public network. Such a public utility model of networking is being debated worldwide, and in the United States underserved regions have embraced it first.

\section{FiberAfrica: A Proposed Model for BROADBAND ACROSS AFRICA FOR \$1/CAPITA}

Extending the open access idea with a leapfrog model, what would greenfield village-level (multi-megabit) broadband across most of Africa cost? Detailed analysis indicates that in the absence of policy and regulatory add-on costs, only $\sim \$ 1 /$ capita one-time investment! While this seems fantastically low and affordable, this only provides connectivity up to a village or school, where it would be shared by many people. This includes new fiber between all the towns/cities (over 70,000 km core fiber), opto-electronics for 
$100 \mathrm{~Gb} / \mathrm{s}$ backbone, core wireless hubs distributed via a GIS optimization, and second hop wireless transmitters per village cluster; this excludes end-user receivers or computers. Technical and business model details are available online in a discussion note ("FiberAfrica") [11], which also highlights the many political and economic challenges for any similar system.

The calculations for Africa are based on several insights and realizations:

- Build at the right scale with the right technologies. It is ironic that for new builds, providing gigabits of connectivity is cheaper than providing megabits. While intercity links can be built cheaper using wireless backhauls, the cost differential ratio is lower than capacity differential.

- Do not just build a backbone. Without access, a backbone is of limited value. Fixed broadband wireless can be very inexpensive to link to the fiber backbone, and optimal designs may include two stages of wireless: WiMax from the optical fibers followed by WiFi over short distances. This is one reason transnational fiber proposals like EASSy are only interim solutions as their connectivity is geared toward select urban areas.

- Share the network. On an Internet scale, many developing countries are smaller than a single city in the West. Aggregating and sharing traffic as well as server farms and international gateways can reduce costs dramatically; there are technical solutions to the concerns of security, national sovereignty, and so on.

- Improve the business model via open access. Instead of profit maximization per se, maximum penetration at lowest cost (with appropriate returns) is a better model. Open access is now recognized as important for Africa; the World Bank has asked the EASSy consortium for this, instead of the traditional business model of a "closed club" of the incumbents.

\section{CONCLUSION}

Emerging regions are where much of the growth in telecommunications services is occurring. Most networking and ICT companies are focusing on the "next billion" users, but this masks the even more billions of users who need dramatically less expensive solutions than today's. At some point, the market will be driven not by the technology or its costs but by new applications and services, which will be enabled by the ICT. Parallel shifts might include moving from high margins to high volumes, and some emerging regional governments are focusing not merely on new technologies such as wireless, but on largescale initiatives (e.g., Macedonia is talking of a country-wide mesh network).
The portfolio of current technologies is sufficient for enormous growth in emerging regions, but universal availability (let alone affordability) will remain elusive for decades even at growth rates of tens of percentage points under businessas-usual scenarios. This is especially true for Internet access, never mind broadband, which, unlike voice communications, almost never has universal service obligations. This domain requires innovative policy and business models as technology alone is unlikely to provide the answer.

\section{ACKNOWLEDGMENTS}

The author gratefully acknowledges discussions and feedback from several colleagues including Prof. Raj Reddy (CMU), Dr. V. S. Arunachalam (CSTEP), Anders Comstedt (Stokab), and Prof. Eswaran Subrahmanian (CMU/NIST). Thanks are also due to the anonymous reviewers and editors, who helped scope this article and provided valuable suggestions for presentation, format, and emphasis.

\section{REFERENCES}

11] R. Tongia, E. Subrahmanian, and V. S. Arunachalam Information and Communications Technology for Sustainable Development: Defining a Global Research Agenda, Bangalore: Allied Press, 2005.

[2] ITU, "World Telecommunication Development Report 2003 - Access Indicators for the Information Society," ITU, Geneva, Switzerland, Dec. 2003.

[3] G. Weigel and D. Waldburger, "ICT4D - Connecting People for a Better World. Lessons, Innovations and Perspectives of Information and Communication Technologies in Development," Berne: Swiss Agency for Development and Cooperation and Global Knowledge Partnership, 2004

[4] T. O'Reilly, What Is Web 2.0? Design Patterns and Business Models for the Next Generation of Software, O'Reilly, 2005

[5] S. Bradner, "NGN: Replacement or Evolution?," Harvard Univ., Sept. 12, 20052005

[6] R. Tongia, "Why is Connectivity in Developing Regions Expensive: Policy Challenges more than Technical Limitations?," 15th Int'l. Conf. World Wide Web, Edinburgh, U.K., 2006

[7] J. Peha, "Approaches to Spectrum Sharing," IEEE Commun. Mag. vol. 43, no. 2, 2005, pp. 10-12.

[8] D. Cabric et al., "Spectrum Sharing Radios," IEEE Circuits and Sys., vol. 6, no. 2, 2006, pp. 30-45.

[9] A. Comstedt, E. Osiakwan, and R. Southwood, "Options for Improving Backbone Access in Developing Countries (with a Focus on Sub-Saharan Africa) (Final Draft)," InfoDev, Washington, DC, Aug. 2005.

[10] N. Frigo, "Niche Player or Future Broadband Access Network Of Choice?: What's in the Cards for Fiber-tothe-Home?," OFC 2004, Los Angeles, CA, 2004.

[11] R. Tongia, "Reducing One Aspect of the Digital Divide - Connectivity (Introducing the FiberAfrica Proposal A Leapfrog Open Access Network)," 2005.

\section{BIOGRAPHY}

RAHUL TONGIA [M] (tongia@cmu.edu) is a faculty member at Carnegie Mellon University (CMU) in the School of Computer Science, and associate director of TechBridgeWorld, the CMU initiative on technology and human development. He has an Sc.B. in electrical engineering from Brown University and a Ph.D. in engineering and public policy from CMU. His interdisciplinary research and teaching focus on the technology, policy, regulation, security, and impact of infrastructure, especially for developing regions; he also plays an active advisory role for governments, utilities, and other stakeholders around the world.
The portfolio of current technologies

is sufficient for

enormous growth in emerging regions,

but universal

availability (let alone affordability) will remain elusive for decades even at growth rates of tens of percentage points under business-asusual scenarios. 